\title{
A COMPARISON OF FINITE ELEMENT SIMULATION AND EXPERIMENTAL RESULTS FROM REINFORCED CONCRETE COLUMNS WRAPPED WITH FIBRE-REINFORCED POLYMER SUBJECTED TO BLAST LOADING
}

\author{
JESLIN QUEK ${ }^{1}$, LIU CHUNLIN $^{2}$, JOHN VINCENT MUSNGI $^{1} \&$ PAVITHRA BUDDIKA MALALASEKARA $^{1}$ \\ ${ }^{1}$ Fyfe Asia Pte Ltd. \\ ${ }^{2}$ K\&C Protective Technologies Pte Ltd.
}

\begin{abstract}
Fibre-reinforced polymer (FRP) as a protective hardening system has now become more commonly used in enhancing the capacity of reinforced concrete (RC) elements against blast loadings. Wrapping RC columns with FRP, depending on the wrapping configuration, will result in additional axial, moment and shear capacity. The FRP also prevents debris from being blown off and serves as a catcher system which minimises the possible cause of injuries/casualties in the event of blast. While analytical models built into popular finite element modelling (FEM) software are widely used to simulate and analyse the effects of a blast load to a structural element, little work has been carried out to validate the results of such analysis through experimental means. This paper examines the effect of blast loadings onto RC columns wrapped with FRP. The behaviour of the FRP-wrapped RC columns subjected to blast loading is simulated using finite element analysis. Results from the finite element simulation are compared to the corresponding wrapping configuration from actual experimental results. The comparison validates the reliability of using finite element analysis in predicting the response of FRP-wrapped $\mathrm{RC}$ columns subjected to blast loading.

Keywords: blast mitigation, fibre-reinforced polymer, finite element simulation.
\end{abstract}

\section{INTRODUCTION}

As the number of terrorist attacks around the globe has risen steadily over the past few decades, there has been an increase in efforts to make both existing and new structures 'stronger' from an engineering perspective, so that they are able to withstand certain level of blast loads. Singapore presents a leading example where the government has provided a set of guidelines [1] through its new Infrastructure Protection Act and made it mandatory for all critical structures, both new and existing, to incorporate structural resiliency against blast effects through engineering design [2].

As a result, numerous protective hardening measures have been adopted by designers to enhance the capacity of structural elements against blast loads. However, when it comes to blast resilience design of a structure, some critical paradigms such as feasibility, location, site constraints and overall security measures need to be assessed holistically and weighed against respective costs. The asset owners, in particular, are sensitive towards additional costs incurred for development of engineering solutions for blast-resistant structures. As such, the need for high-performance materials that could be installed relatively easily for both existing and new structures has become significant. Fibre-reinforced polymer (FRP) is a material that fits into this category.

While FRP is well known and proven itself as a material for strengthening existing structures for static loads [3], it has gained a significant recognition as a sound material for protective hardening or blast mitigation. As a high-tensile strength material that is extremely 
light weight, FRP presents an effective solution for blast resilience structures [4]. In addition, the flexibility of the material allowing it to be basically 'wrapped' on to a structural element brings in significant advantages when it comes to installation [3].

\section{FRP FOR PROTECTIVE HARDENING}

Numerous mathematical and analytical models have been developed to analyse the behaviour of structures subjected to blast load effects. Single-Degree-of-Freedom Blast Effects Design Spreadsheets (SBEDS) is a popular analytical tool developed and distributed by the U.S. Army Corps of Engineers, which allows designers to obtain the responses of structural elements that are subjected to a blast load effect [5].

Subsequently, analytical models to predict the responses of structural elements enhanced with FRP were developed. FWrapSDOF [6] is such a model which allows the designers to compare the responses with the Tyfo ${ }^{\circledR}$ Fibrwrap ${ }^{\circledR}$ System, a proprietary FRP composite system, and to determine its effectiveness.

One of the main drawbacks of these analytical models is that they require the designer to input the details of the blast load (e.g. peak pressure and impulse or charge weight and standoff distances) in order to obtain the analysis results. Further, the responses are for isolated structural elements. These will hinder the structural engineer's ability to obtain a holistic view of the behaviour of the overall structure.

Efforts have been made to overcome the above limitations by incorporating blast force prediction models in popular Finite Element (FE) software packages. Popular FE programs such as ABAQUS have blast pressure forecast models such as CONWEP [7] as an in-built feature. In addition, these software packages are capable of running Coupled EulerianLagrangian (CEL) models which can be used to simulate the propagation of a blast wave and its effect on the surrounding structures.

However, there have not been many efforts to validate the simulation results of a blast scenario obtained from FE software packages through practical experiments. The objective of this paper is to validate the use of ABAQUS software package for both near-contact and distant blast scenarios through field experiments. Validation of this approach is critical, considering the level of difficulty associated in conducting field experiments to analyse various blast scenarios compared to other field experiments. In addition, the simulations are used to showcase the effectiveness of Tyfo ${ }^{\circledR}$ Fibrwrap ${ }^{\circledR}$ System, an FRP composite system, as a protective hardening material, which are validated through the same experiments.

\section{EXPERIMENTAL SET-UP}

Two independent field experiments were chosen to simulate a distant and a near-contact blast scenario separately. A Shock-Tube test, which was designed to analyse the effects of a blast wave originating from a far distance on reinforced concrete (RC) columns, was used for the first case. Pressures exerted from the simulated blast wave on the columns together with the key indicators corresponding to the response of the columns were recorded. The same experiment was carried out after installing the Tyfo ${ }^{\circledR}$ Fibrwrap ${ }^{\circledR}$ System on the column to evaluate the effectiveness of the composite FRP system as a protective hardening measure.

For the near-contact blast scenario, RC columns pre-installed with specific combination of Tyfo $^{\circledR}$ Fibrwrap ${ }^{\circledR}$ System were subjected to a blast impact resulting from $20 \mathrm{~kg}$ equivalent TNT. As an experiment designed for a specific party with an explicit scenario in mind, the objective of this experiment was twofold. Firstly, the condition of the columns after the blast impact was to be evaluated. Secondly, the impact on the Tyfo ${ }^{\circledR}$ S Epoxy, which was a part of 
the Tyfo ${ }^{\circledR}$ Fibrwrap ${ }^{\circledR}$ Composite system, from the instantaneous high heat generated from the blast load was also to be noted and recorded. The speculations on whether the epoxy would melt prior to having any effect on the column needed to be disproved through the experiment.

Both these experiments were simulated using the CONWEP model available in ABAQUS. The objective was to validate the experimental results through the simulations, such that ABAQUS could be used as a reliable tool to understand and evaluate the effects of a blast scenario.

\subsection{Shock-Tube test}

The RC columns with an aspect ratio of 2:1 were tested at the Shock-Tube test facility at the University of Ottawa [8]. The columns were vertically oriented and attached to the ShockTube from both ends using threaded steel rods. This set-up was specifically designed to simulate ideal simple support conditions. One of the longer faces of the columns was selected to receive the blast loads, which allowed for tests on the column's weaker axis. A Load Transfer Device was used to transfer the blast load to the columns. Figure 1 provides the overall set-up of the column fixed on to the Shock-Tube, and Fig. 2 showcases the direction of blast loading together with the column's reinforcement detailing.

Two cases from the tests were selected for this paper: an RC column section without the Tyfo $^{\circledR}$ Fibrwrap ${ }^{\circledR}$ System, control specimen, and another column with the Tyfo ${ }^{\circledR}$ Fibrwrap $^{\circledR}$ System as the retrofit for blast resiliency. In both cases, the columns were $300 \mathrm{~mm}$ wide and $150 \mathrm{~mm}$ deep and were reinforced with eight deformed bars of nominal diameter of $11.3 \mathrm{~mm}$

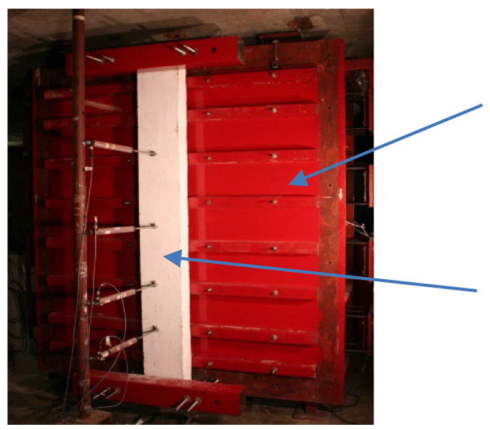

Load Transfer Device To enable the transfer of blast pressure

Column supported at the ends

Figure 1: Shock-Tube test set-up.

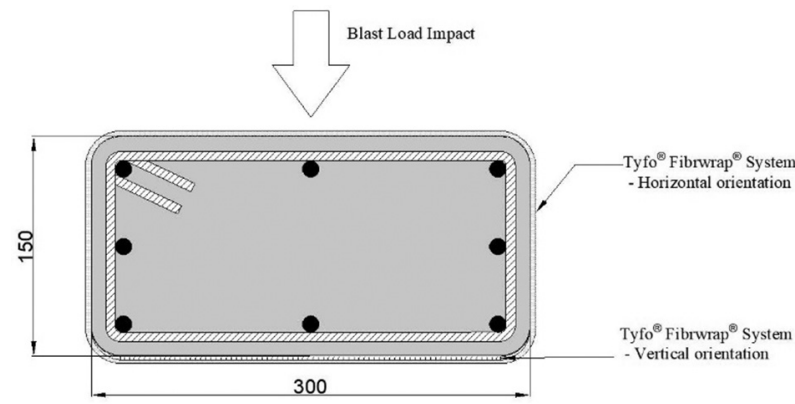

Figure 2: Column reinforcement and FRP retrofit details. 
Table 1: Material properties for Shock-Tube test.

\begin{tabular}{|c|c|c|}
\hline Material & Property & Value \\
\hline Concrete - control specimen & Compressive strength & $38.5 \mathrm{MPa}$ \\
\hline Concrete - retrofitted specimen & Compressive strength & $30.5 \mathrm{MPa}$ \\
\hline \multirow{2}{*}{ Longitudinal reinforcement } & Yield strength & $582 \mathrm{MPa}$ \\
\hline & Failure strength & $722 \mathrm{MPa}$ \\
\hline \multirow[t]{3}{*}{ Transverse reinforcement } & Yield strength & $518 \mathrm{MPa}$ \\
\hline & Failure strength & $656 \mathrm{MPa}$ \\
\hline & Ultimate tensile strength & $575 \mathrm{MPa}$ \\
\hline \multirow[t]{2}{*}{ Tyfo ${ }^{\circledR}$ SEH-51A } & Failure strain & $2.2 \%$ \\
\hline & Modulus & $26,100 \mathrm{MPa}$ \\
\hline
\end{tabular}

longitudinally. Horizontal links fabricated from 6.3-mm-diameter smooth steel wires were placed at a spacing of $150 \mathrm{~mm}$. The concrete used was a normal strength concrete for all specimens. Both steel and concrete were tested to obtain the actual material properties and are listed in Table 1.

For the FRP composite retrofit, the material used was Tyfo ${ }^{\circledR} \mathrm{SEH}-51 \mathrm{~A}$ and the specified properties of this material are found in Table 1. As a unidirectional Glass FRP (GFRP) material, Tyfo ${ }^{\circledR}$ SEH-51A material was oriented in a such way that it consisted of two separate layers of the composite: the first layer was installed 'vertically' parallel to the column's longitudinal axis on the opposite to the side receiving the blast load; the last layer was installed 'horizontally', oriented perpendicularly to the column's main axis, encompassing the vertical layer and providing a confinement effect. The corners of the retrofitted column specimen were rounded to a radius of $20 \mathrm{~mm}$.

The time history data for pressure, maximum displacement of the column and strains of the Tyfo ${ }^{\circledR}$ Fibrwrap ${ }^{\circledR}$ System were measured during the experiment. Further, high-speed cameras were installed to record the responses of the columns.

\subsection{Near-contact blast scenario}

In a separate experiment, circular RC columns installed with the Tyfo ${ }^{\circledR}$ Fibrwrap ${ }^{\circledR}$ System were tested in 2016 by subjecting them to a blast load generated from $\mathrm{C} 4$ material simulating $20 \mathrm{~kg}$ equivalent TNT at Energetic Materials Research and Test Centre (EMRTC)'s test facility in New Mexico, USA. The columns were cast in Singapore and were sent to the testing facility in the USA.

The columns were $1 \mathrm{~m}$ in diameter and were reinforced with 12 longitudinal deformed bars which were $32 \mathrm{~mm}$ in diameter. Horizontal links were made of deformed bars of $10 \mathrm{~mm}$ diameter spaced at $250 \mathrm{~mm}$. For this experiment, two identical columns were fixed on to a 1.3-m-wide, 1.3-m-long and 450-mm-thick RC footing.

As an experiment with a specific objective in mind as stated by the client, but cannot be revealed due to confidentiality agreements, the circular columns were retrofitted with two different types of materials of the Tyfo ${ }^{\circledR}$ Fibrwrap ${ }^{\circledR}$ System. As the first layer, the entire column surfaces were covered with Tyfo ${ }^{\circledR}$ SCH-11UP, a Carbon FRP (CFRP) material. This was followed by Tyfo ${ }^{\circledR}$ SEH-51A material installed only for a height of $2 \mathrm{~m}$ measured from the 


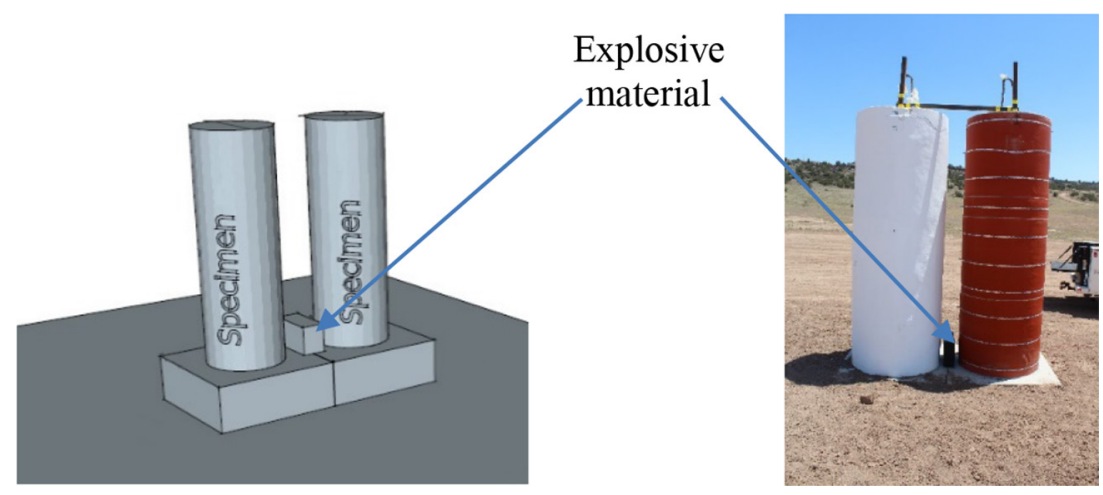

Figure 3: Test set-up for near-contact blast scenario.

Table 2: Material properties for near-contact blast test.

\begin{tabular}{lll}
\hline Material & Property & Value \\
\hline Concrete & Compressive strength & $60 \mathrm{MPa}$ \\
Longitudinal reinforcement & Yield strength & $500 \mathrm{MPa}$ \\
Transverse reinforcement & Yield strength & $500 \mathrm{MPa}$ \\
& Ultimate tensile strength & $575 \mathrm{MPa}$ \\
Tyfo $^{\circledR}$ SEH-51A & Failure strain & $2.2 \%$ \\
& Modulus & $26,100 \mathrm{MPa}$ \\
Tyfo $^{\circledR}$ SCH-11UP & Ultimate tensile strength & $1062 \mathrm{MPa}$ \\
& Failure strain & $1.1 \%$ \\
\hline
\end{tabular}

surface of the footing. The materials were installed in a predetermined configuration, in both 'vertical' and 'horizontal' orientations, where the fibres were oriented parallelly and perpendicularly to the column's main axis, respectively. Finally, as a part of the specified configuration, the columns were applied with two different kinds of protective layers which are usually used for fire protection. Figure 3 illustrates the final test set-up, and Table 2 summarises the material properties.

\section{SIMULATION AND COMPARISON OF RESULTS}

ABAQUS CAE was used to create three-dimensional models to simulate both experiments separately. The models were created to represent the actual conditions with the dimensions obtained from the experimental set-ups.

\subsection{Shock-Tube test simulation}

The pressure time history recorded from the Shock-Tube test was provided as the input of blast pressure for the simulation of Shock-Tube test. The blast load was modelled as a uniformly distributed pressure across the Load Transfer Device, which was then transferred to the column. The simulation was carried out monitoring the response of the column up to a time of $0.3 \mathrm{~ms}$ from the commencement. 


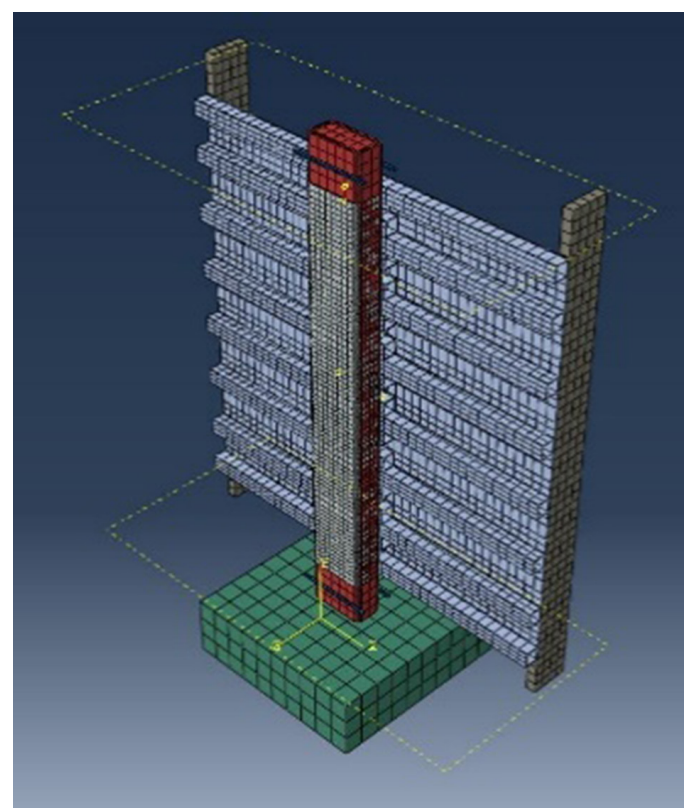

Figure 4: Simulation model for Shock-Tube test.

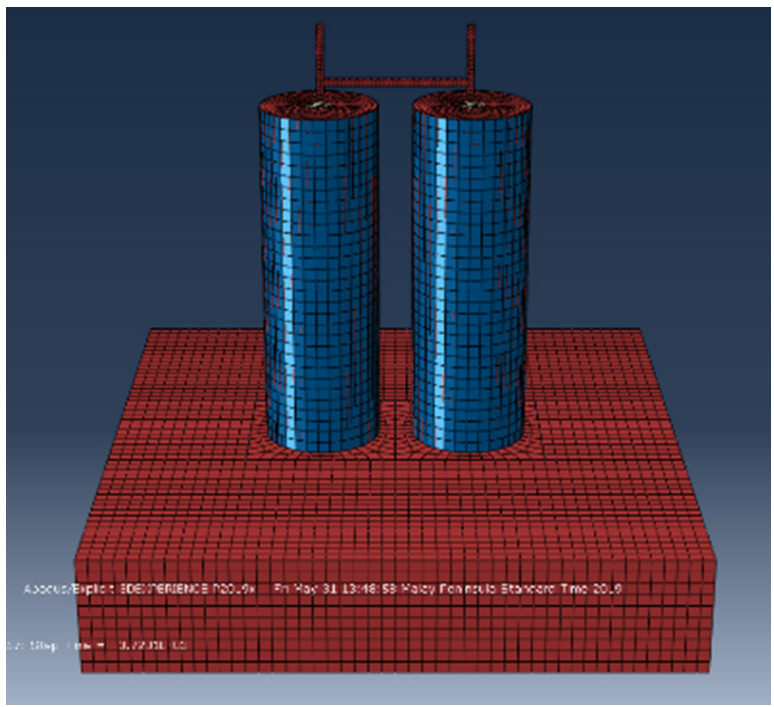

Figure 5: Simulation model for near-contact blast.

The obvious tell-tale sign of columns subjected to simulated blast loads from the ShockTube was the maximum deflection observed approximately at the mid-span position. This was compatible with the expected failure mode. The control specimen showed severe level of failure as the concrete was completely disintegrated at the peak failure location exposing the reinforcement. The displacement was recorded as $197 \mathrm{~mm}$. When the blast load was applied on to the column, it moved away from the Shock-Tube, but had insufficient level of ductility to show any signs of rebound as the failure occurred resulting in a permanent damage. 

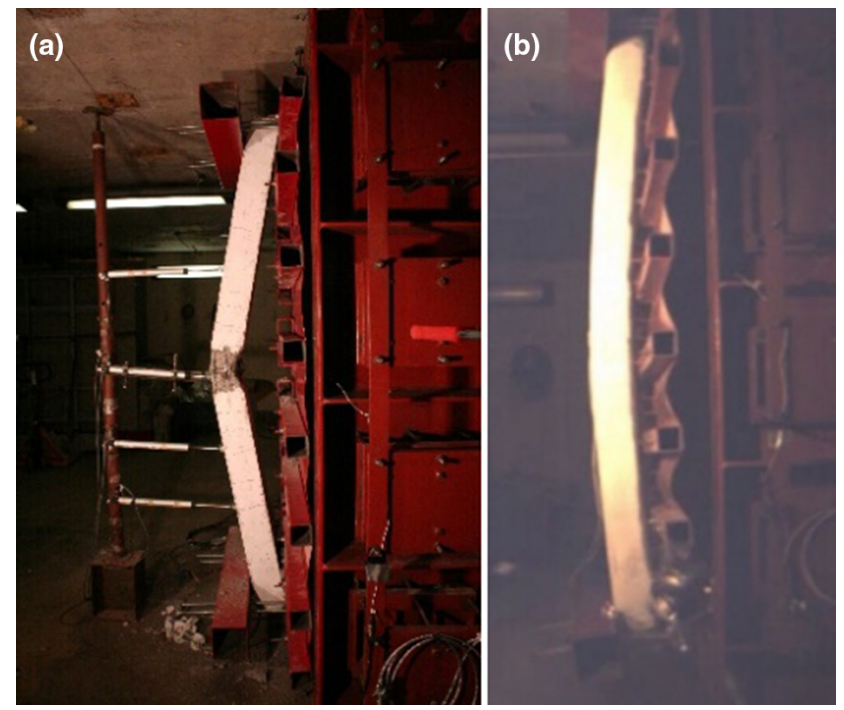

Figure 6a: After the testing of control specimen - max. deflection $197 \mathrm{~mm}$.

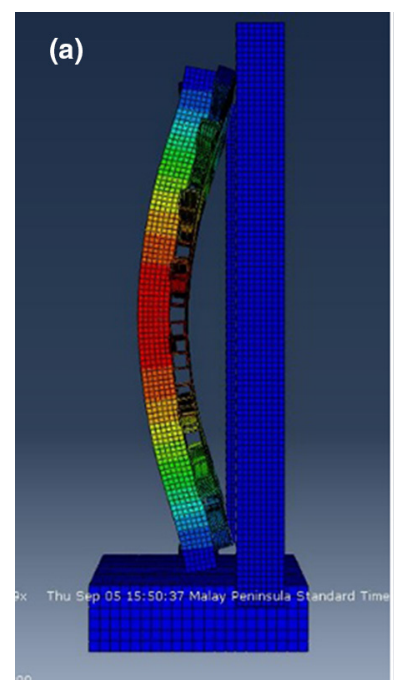

Figure 7a: Simulation of control specimen Figure 7b: Simulation of retrofitted specimen - max. deflection $222 \mathrm{~mm}$.
Figure 6b: After the testing of retrofitted specimen - deflection $99 \mathrm{~mm}$.

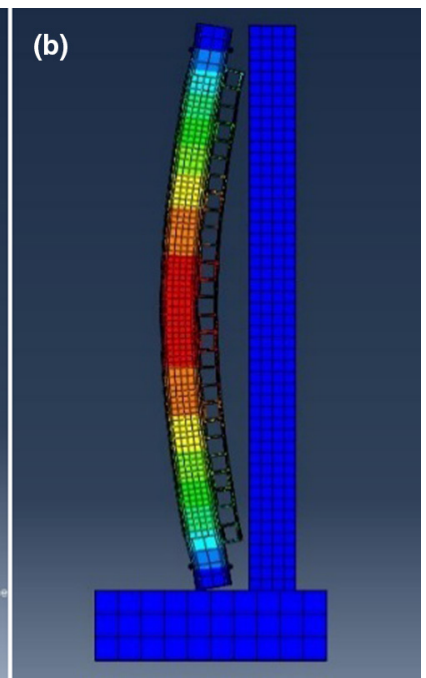

- max. deflection $136 \mathrm{~mm}$.

The other specimen with the Tyfo ${ }^{\circledR}$ Fibrwrap ${ }^{\circledR}$ System displayed increased level of stiffness when facing the blast loads. As the column was impacted by the blast, it moved away from the Shock-Tube face, similarly to the control specimen, but appeared to have an enhanced level of ductility to result in a rebound movement. The final settlement, however, showed a permanent deflection, albeit with reduction nearing to $50 \%$ compared to the control specimen. The peak deflection for this was measured at $99 \mathrm{~mm}$.

Simulation results for both these columns in the Shock-Tube showed remarkable resemblance to the experimental results. Figures 6 and 7 show a comparison of final failure modes 


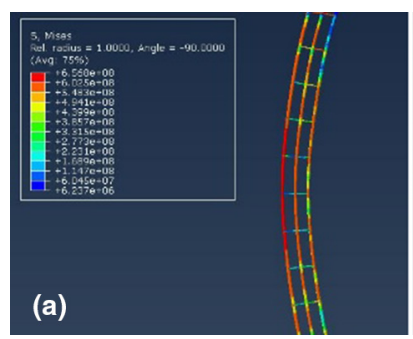

Figure 8a: Maximum reinforcement stress of control section - $657 \mathrm{MPa}$.

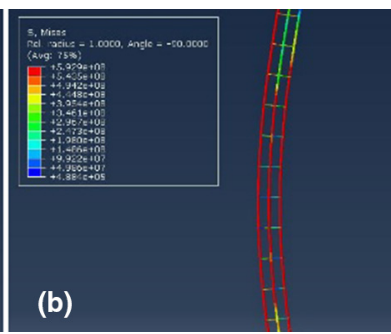

Figure 8b: Maximum reinforcement stress of retrofitted section - $593 \mathrm{MPa}$.

for both control and retrofitted specimens taken from the experiment as well as from the simulation. The maximum deflections that resulted from the simulations showed a deviation compared to the experimental values, resulting in values 222 and $136 \mathrm{~mm}$ for the control and retrofitted specimens, respectively.

Another critical aspect obtained through the simulation was the stresses of steel reinforcement for both cases. The inclusion of Tyfo ${ }^{\circledR}$ Fibrwrap ${ }^{\circledR}$ System clearly lowered the final stress levels of steel and brought down the stress level of steel near to its yield level. As shown in Fig. 8, the maximum stress levels resulting from the simulation for reinforcement of the control specimen and retrofitted specimen were 657 and $593 \mathrm{MPa}$, respectively, presenting a reduction of $9.7 \%$.

\subsection{Near-contact blast simulation}

The in-built CONWEP model in ABAQUS CAE was used to simulate the near-contact blast scenario. The propagation of the blast, as predicted by the software, is shown in Fig. 9. As there was no reference specimen in this experiment, the first part of the simulation was aimed at modelling the actual experiment where columns were installed with Tyfo ${ }^{\circledR}$ Fibrwrap ${ }^{\circledR}$ System. The second part of the simulation was used to answer the 'what-if' question over the behaviour of the column without the Tyfo ${ }^{\circledR}$ Fibrwrap ${ }^{\circledR}$ System.

A somewhat severe level of concrete failure was expected for the near-contact blast specimen, and therefore, the objective was to evaluate post-blast conditions of the column specimen. Further, the condition of the Tyfo ${ }^{\circledR}$ Fibrwrap ${ }^{\circledR}$ System was a critical observation, as the experiment was aimed at evaluating its state after subjecting it to a high level of heat energy generated from the blast.

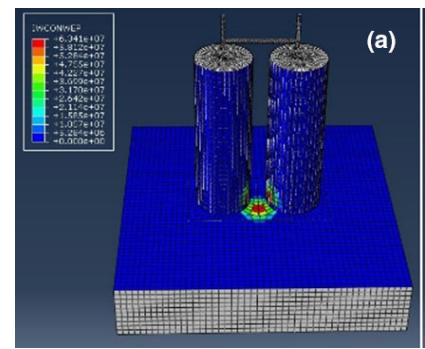

Figure 9a: Propagation of the blast - initial point.

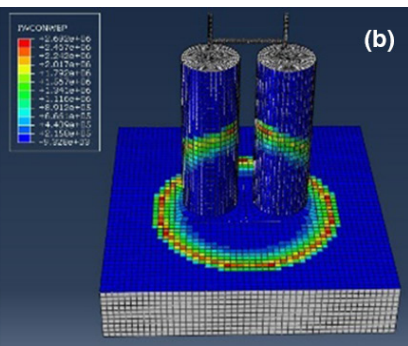

Figure 9b: Propagation of the blast - moving away from columns.

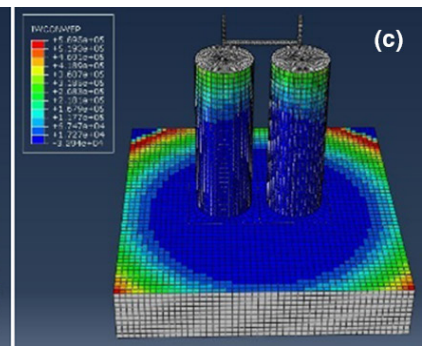

Figure 9c: Propagation of the blast - blast wave moved away from the area. 


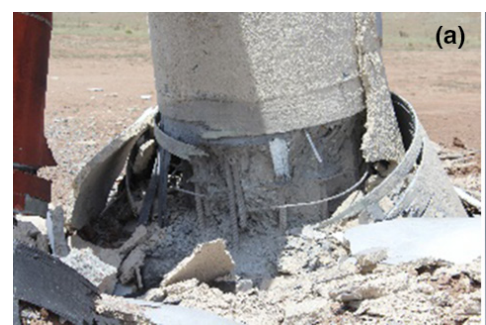

Figure 10a: Damage on the column from the testing.

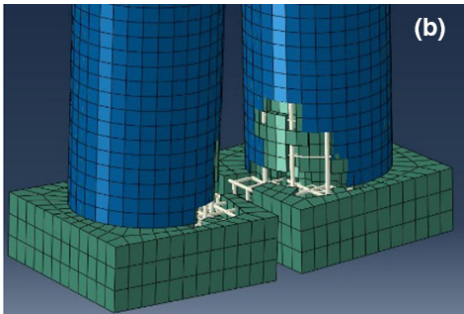

Figure 10b: Simulated damage on the column.

A comparison between test and simulated damage can be made by referring to Fig. 10. The experiment resulted in a concrete failure measuring to a maximum depth of $132 \mathrm{~mm}$. The simulation resulted in a near-perfect level of failure, with the maximum depth of failed concrete measuring $135 \mathrm{~mm}$.

Since there was no control specimen (i.e. a specimen without the retrofit), a separate simulation was used to evaluate the condition of a similar column subjected to the same blast load. The simulations revealed (Fig. 11) that without the retrofit, the concrete across the section will fail completely which will result in a catastrophic failure as there will be no residual strength in the column.

In addition, it is critical to note that the Tyfo ${ }^{\circledR} \mathrm{S}$ epoxy used as part of the Tyfo ${ }^{\circledR}$ Fibrwrap $^{\circledR}$ Composite system did not melt or disintegrate as a result of exposure to the high level of heat generated. The system worked as complete composite, without melting in the face of high heat, just as intended.

Conclusions

Comparisons of field tests and simulations using ABAQUS for near-contact and distant blast scenarios have shown the effectiveness of FE simulations to understand and evaluate conditions resulting from a blast wave. Simulations provided an added advantage as they enabled one to observe the propagation of the blast wave with respect to time and its impact on the surrounding structures.

The deviation between results from the distant blast test and simulation seemed to be somewhat excessive for the control specimen at $37 \%$, while for the retrofitted column it was lower at $12.7 \%$. Even with this level of deviation for the control specimen, it still provides a critical perspective in understanding the overall effect of structural element without any protective measures. Further, decreased stress levels of steel, as shown in the simulation, are

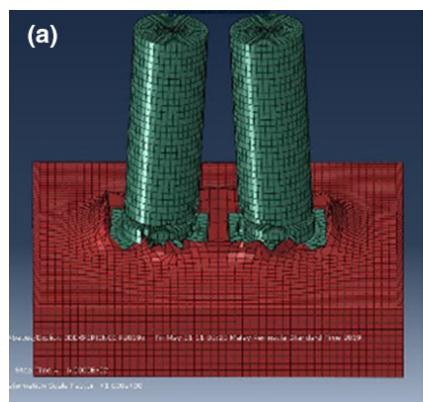

Figure 11a: Simulation results without the retrofit.

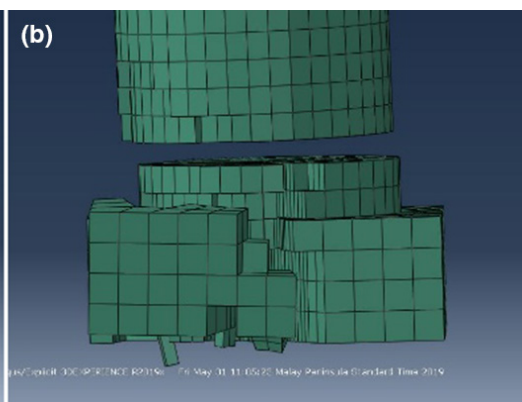

Figure 11b: Simulation results - complete concrete failure without the retrofit. 
robust inputs for an engineering design for blast resiliency, when used with an appropriate safety factor. The comparison of simulations and experimental results provides the basis for an appropriate safety factor.

In general, carrying out field experiments for blast scenarios poses increased level of difficulty due to obvious aspects in security clearances, availability of materials, costs, etc. Under these circumstances, simulations such as the above present a sound alternative towards analysing and evaluating the effects of a structure subjected to a blast load. Further, it allows the designers to come up with solutions with sound engineering judgement.

\section{REFERENCES}

[1] Joint Operations Group - Ministry of Home Affairs, Guidelines for Enhancing Building Security in Singapore (GEBSS). https://www.mha.gov.sg/docs/default-source/others/ mha_guidelines_for_enhancing_building_security_in_singapore_2018.pdf. Accessed on: 22 Dec. 2019.

[2] Singapore Statutes Online, Infrastructure Protection Act 2017 (No. 41 of 2017), Government of Singapore. https://sso.agc.gov.sg/Acts-Supp/41-2017/Published/20171031? DocDate=20171031. Accessed on: 25 Jan. 2020.

[3] ACI committee 440, Guide for the design and construction of externally bonded FRP systems for strengthening existing structures (ACI 440.2R-17), 2017.

[4] The Concrete Society, Design guidance for strengthening concrete structures using fibre composite materials, Technical Report 55 (3rd Edition). The Concrete Society, Camberley, 2012.

[5] U.S. Army Corps of Engineers, Structures to Resist the Effects of Accidental Explosions (UFC 3-340-02), 2008.

[6] Quek, J., \& Ow, M.C., SDOF analysis of protective hardening design for reinforced concrete columns using fibre reinforced polymer wrap. Proceedings of the Fourth AsiaPacific Conference on FRP in Structures (APFIS 2013), 2013.

[7] Kingery, C. N., Bulmash, G., \& U.S. Army Ballistic Research Laboratory. Air blast parameters from TNT spherical air burst and hemispherical surface burst. Aberdeen Proving Ground, MD: Ballistic Research Laboratories, 1984.

[8] Jacques, E., Lloyd, A., Imbeau, P., Palermo, D., \& Quek, J., GFRP-retrofitted reinforced concrete columns subjected to simulated blast loading. Journal of Structural Engineering, 141(11), 04015028, 2015. doi:10.1061/(ASCE)ST.1943-541X.0001251 